\title{
Papers
}

\section{Community based retrospective study of sex in infant mortality in India}

\author{
R Khanna, A Kumar, J F Vaghela, V Sreenivas, J M Puliyel
}

\begin{abstract}
Objective To determine whether the imbalance in the sex ratio in India can be explained by less favourable treatment of girls in infancy.

Design Analysis of results of verbal autopsy reports over a five year period.

Setting Community health project in urban India. Main outcome measures Deaths from all causes in infants aged less than 1 year.

Results The sex ratio at birth was 869 females per 1000 males. The mean infant mortality was 1.3 times higher in females than in males (72 v 55 per 1000$)$. Diarrhoea was responsible for $22 \%$ of deaths overall, though twice as many girls died from diarrhoea. There were no significant differences in the numbers of deaths from causes such as birth asphyxia, septicaemia, prematurity, and congenital anomalies. In $10 \%$ of deaths there was no preceding illness and no satisfactory cause was found. Three out of every four such deaths were in girls.

Conclusions The excess number of unexplained deaths and deaths due to treatable conditions such as diarrhoeal disease in girls may be because girls are regarded and treated less favourably in India.
\end{abstract}

\section{Introduction}

Grave concern is being expressed by social scientists and health professionals about the adverse sex ratio in India. According to the 2001 Indian census there are only 933 females per 1000 males. ${ }^{1}$ Ordinarily women outnumber men, possibly because the extra X chromosome they carry makes them less susceptible to infectious diseases and protects them against sex linked recessive disorders. ${ }^{2}$

This inversion of the sex ratio in India suggests the existence of sex discrimination. The practice of antenatal selection and termination of female pregnancies has persisted, ${ }^{3}$ despite the banning of sex determination tests under the Pre Natal Diagnostic Techniques Act (PNDT) 1994. ${ }^{4}$ After birth mortality is also higher in female infants, girls, and young women. ${ }^{5}$ Girls are 30-50\% more likely than boys to die between their 1st and 5th birthdays. ${ }^{6}$ Various studies have previously shown that compared with boys, female children are often brought to health facilities in more advanced stages of illness, are taken to less qualified doctors when they are ill, and have less money spent on medi- cines for them. ${ }^{7}$ A study in Punjab showed that during the first two years of a child's life, parents spent 2.3 times more on health care for sons than for daughters. ${ }^{8}$

In a community based study we looked at the causes of infant death in girls compared with in boys. If there is discrimination and neglect, there should be an increase in deaths in the neglected sex due to causes that would not be fatal with appropriate care, whereas death rate for diseases with grave prognosis would be equal in both the sexes.

\section{Methods}

For the past 20 years the community health department of St Stephen's Hospital has been providing comprehensive health care in three socioeconomically deprived areas of Delhi-Sunder Nagari, Tahirpur, and Amar Colony-with a combined population of about 64000 people. These areas on the outskirts of the city are relocation settlements started 20 years ago. Most of the residents came to Delhi 25 years ago as migrant workers and were living in inner city slums before being relocated here by the government. ${ }^{9}$ The average per capita income of a household in these areas is about 600 rupees per month (£8, $\$ 13, € 11$ ). Table 1 shows the data on crude birth rate in the area for the study period, with the average rate being 22.3 live births per 1000 population. The population is $66 \%$ Hindu and 34\% Muslims, and the birth rates in the two communities are also shown in table 1.

The department has a multidisciplinary staff of about 40, consisting of doctors, public health nurse, auxiliary nurse midwives, and other health personnel. As the midwives have been working in the community for the past 7-10 years, their acceptability and rapport with the families is high. They provide health education and collect information on births, deaths, pregnancy, immunisation, and family planning. They record this information in family based folders and then in the registers of their respective areas. Finally the data are entered into the computerised management information system of the department that was established six years ago. Here we are analysing data for the five year period from January 1997 to December 2001.

Verbal autopsies are used for finding out the cause of each death. Every month the midwives discuss any cases with a visiting paediatrician from the hospital, and the probable cause of death is noted in the records.
Department of Community Medicine, $\mathrm{St}$ Stephen's Hospital, Tis Hazari, Delhi 110054, India R Khanna registrar A Kumar consultant and head of department

J F Vaghela consultant

Department of Biostatistics, All India Institute of Medical Science, New Delhi 110029 , India

V Sreenivas assistant professor

Department of Paediatrics, St Stephen's Hospital, Tis Hazari

J M Puliyel consultant and head of department

Correspondence to: A Kumar amodkumar@ vsnl.com

bmj.com 2003;327:126 
Table 1 Crude birth rate in study area by year and community (2001 only)

\begin{tabular}{lccc} 
& Total live births & Population & Crude rate (per 1000 population) \\
\hline 1997 & 1534 & 60967 & 25.16 \\
\hline 1998 & 1417 & 62383 & 22.71 \\
\hline 1999 & 1434 & 63385 & 22.62 \\
\hline 2000 & 1413 & 64744 & 21.82 \\
\hline $2001:$ & & \\
\hline All $^{*}$ & 1214 & 62762 & 19.34 \\
\hline Hindus & 733 & 40896 & 22.24 \\
\hline Muslims & 481 & 21624 &
\end{tabular}

*Includes 229 Sikhs and 13 Christians.

\section{Table 2 Distribution of total births and infant deaths*}

\begin{tabular}{lccc} 
& Total & Male (\%) & Female (\%) \\
\hline Live births & 7012 & $3752(54)$ & $3260(46)$ \\
\hline Infant deaths & 442 & $208(47)$ & $234(53)$ \\
\hline Infant mortality (per 1000 live births) & 63 & 55 & 72 \\
\hline
\end{tabular}

${ }^{*}$ Comparison of mortality of two sexes: Yates corrected $\chi^{2}=7.61, P<0.05$.

In cases where information seemed inadequate, the midwife or a doctor from the centre revisited the house to get more details. The record of deaths maintained by the midwives forms the basis of this study.

We examined the number of live born infants and infant deaths each year and grouped deaths by sex and analysed the causes of death. All cases of death of children reported as sudden and without any preceding illness were categorised as "unexplained deaths." We categorised cases in which the cause of death could not be ascertained-for example, when the family had moved out of the area-as "data not available."

We examined overall infant mortality (all deaths in children aged under 1 year per 1000 live births) for each of the five years under study and compared overall mortality and cause specific mortality by sex. Analysis was done with EPI-6 statistical software. Yates corrected $\chi^{2}$ test was used for comparing the cause specific infant mortality among the two sexes. $\mathrm{P}<0.05$ was considered to be significant. We calculated odds ratios with corresponding confidence intervals for deaths from different causes by sex.

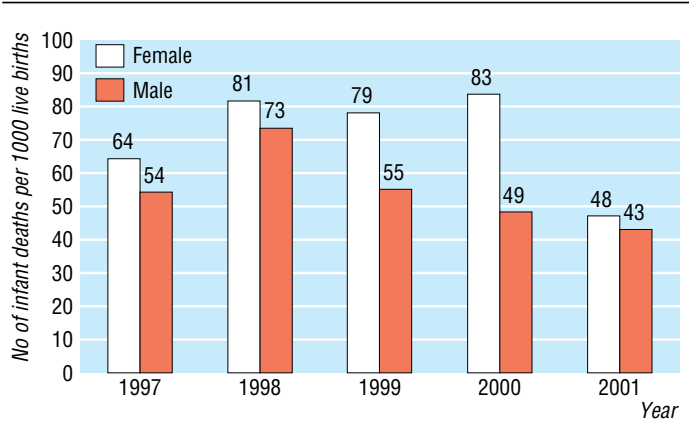

Infant mortality by year in study area

\section{Results}

Table 2 shows the numbers of live births and infant deaths by sex. There were 7012 live births, 3752 boys and 3260 girls. The sex ratio at birth in the area was 869 girls: 1000 boys. There were 442 deaths in children under the age of 1 year, 234 girls (53\%) and 208 boys $(47 \%)$. The average mortality for the period was 63 per 1000 live births. The figure shows the infant mortality each year for the two sexes. The mean mortality for girls was 1.3 times that of the boys (72 v55 per 1000).

The most common causes of death were diarrhoea (21.5\%), birth asphyxia (14\%), immaturity (12.4\%), acute respiratory infection (10.9\%), and unexplained deaths $(10 \%)$ (table 3). Fourteen deaths were classified under other causes. There was significant difference in mortality between girls and boys for diarrhoea and unexplained deaths (table $3, \mathrm{P}<0.05$ ). There was no significant difference in deaths due to less preventable and less treatable conditions like birth asphyxia, immaturity, septicaemia, and congenital anomalies. The largest difference between the two sexes was for unexplained death. Here the mortality in female infants was more than three times that in male infants. Half of the deaths (22/44) in this group occurred in the first month of life. Nineteen of the 22 deaths due to unexplained causes in neonates were among females.

For diarrhoeal diseases the cause specific mortality in female infants was twice that in male infants. For congenital anomalies and birth asphyxia it was higher

Table 3 Cause of death in 442 infants who died aged $\leq 1$ year

\begin{tabular}{|c|c|c|c|c|c|c|c|c|}
\hline \multirow[b]{2}{*}{ Cause } & \multicolumn{3}{|c|}{ No of deaths } & \multicolumn{2}{|c|}{ Cause specific mortality } & \multirow[b]{2}{*}{ Odds ratio $(95 \% \mathrm{C})$} & \multirow[b]{2}{*}{$\chi^{2}$} & \multirow[b]{2}{*}{$P$ value } \\
\hline & Total & Male & Female & Male & Female & & & \\
\hline Unexplained deaths & 44 & 11 & 33 & 2.93 & 10.12 & 3.48 (1.69 to 7.31 ) & 13.34 & $<0.05$ \\
\hline Diarrhoea & 95 & 32 & 63 & 8.53 & 19.32 & 2.29 (1.46 to 3.59$)$ & 14.42 & $<0.05$ \\
\hline Acute respiratory infection & 48 & 22 & 26 & 5.86 & 7.97 & $1.36(0.75$ to 2.50$)$ & 0.85 & 0.36 \\
\hline High fever & 5 & 4 & 1 & 1.06 & 0.3 & $0.29(0.01$ to 2.70$)$ & 0.55 & 0.46 \\
\hline Malnutrition & 14 & 7 & 7 & 1.86 & 2.14 & 1.15 (0.36 to 3.64$)$ & 0 & 1 \\
\hline Jaundice & 4 & 3 & 1 & 0.79 & 0.3 & $0.38(0.02$ to 4.29$)$ & 0.13 & 0.72 \\
\hline Birth asphyxia & 62 & 34 & 28 & 9.06 & 8.59 & 0.95 (0.56 to 1.61$)$ & 0.01 & 0.93 \\
\hline Immaturity & 55 & 28 & 27 & 7.46 & 8.28 & 1.11 (0.63 to 1.95$)$ & 0.06 & 0.8 \\
\hline Septicaemia & 39 & 20 & 19 & 5.33 & 5.82 & 1.09 (0.56 to 2.14$)$ & 0.01 & 0.91 \\
\hline Congenital anomaly & 37 & 24 & 13 & 6.39 & 3.98 & $0.62(0.30$ to 1.28$)$ & 1.5 & 0.22 \\
\hline Convulsions & 9 & 5 & 4 & 1.33 & 1.22 & $0.92(0.21$ to 3.93$)$ & 0.04 & 0.83 \\
\hline Injury & 5 & 1 & 4 & 0.27 & 1.23 & $4.61(0.49$ to 108.27$)$ & 1.11 & 0.29 \\
\hline 0thers* & 14 & 9 & 5 & 2.39 & 1.53 & 0.64 (0.19 to 2.08) & 0.29 & 0.59 \\
\hline Data not available & 11 & 8 & 3 & 2.13 & 0.92 & $0.43(0.09$ to 1.78$)$ & 0.95 & 0.33 \\
\hline
\end{tabular}

${ }^{*}$ Meningitis with septicaemia (2), strangulated hernia (1), aspiration of feed (1), exanthematous fever (1), birth trauma (1), bleeding from cord with exsanguination

(2), postoperative complication of shunt surgery for hydrocephalus (1), Rh incompatibility (1), sepsis (1), possible reaction to injection given to control vomiting (1). 
Table 4 Comparison of cause specific infant mortality of two communities (Hindus and Muslims)

\begin{tabular}{|c|c|c|c|c|c|c|c|c|}
\hline \multirow[b]{2}{*}{ Cause } & \multicolumn{3}{|c|}{ No of deaths } & \multicolumn{2}{|c|}{ Cause specific mortality } & \multirow[b]{2}{*}{ Odds ratio(95\% Cl) } & \multirow[b]{2}{*}{$\chi^{2}$} & \multirow[b]{2}{*}{$P$ value } \\
\hline & Total & Hindu & Muslim & Hindu & Muslim & & & \\
\hline Diarrhoea & 95 & 64 & 31 & 15.46 & 10.79 & $1.44(0.92$ to 2.27$)$ & 2.43 & 0.12 \\
\hline Unexplained deaths & 44 & 29 & 15 & 7.00 & 5.22 & 1.34 (0.69 to 2.63 ) & 0.60 & 0.44 \\
\hline Septicaemia & 39 & 23 & 16 & 5.56 & 5.57 & 1.00 (0.51 to 1.98$)$ & 0.02 & 0.87 \\
\hline Congenital anomaly & 37 & 28 & 9 & 6.76 & 3.13 & 2.17 (0.98 to 4.95$)$ & 3.60 & 0.06 \\
\hline
\end{tabular}

Table 5 Monthly per capita income of families with infant deaths due to different causes

\begin{tabular}{lc} 
Cause of infant death & $\begin{array}{c}\text { Mean per capita income of families } \\
\text { (rupees) }\end{array}$ \\
\hline Diarrhoeal diseases & 409 \\
\hline Unexplained deaths & 537 \\
\hline Septicaemia & 464 \\
\hline Congenital anomaly & 497 \\
\hline
\end{tabular}

in male than in female infants, though not significantly so.

We also looked at the cause specific mortality in Hindu and Muslim communities (table 4). The average monthly per capita income was 679 rupees in Hindus and 423 rupees in Muslims. There was no significant difference in the cause specific mortality in the two communities for preventable and treatable causes or less preventable causes.

Table 5 shows the mean per capita income of the families in which infant deaths were attributable to various causes. The mean per capita income of families in which infants had died from diarrhoea was the lowest at 409 rupees, and in families in which the deaths were unexplained was the highest at 537 rupees.

\section{Discussion}

\section{Infant mortality in girls}

We have shown that in India there are many cases in which death of a child is sudden, with no preceding history of illness. These deaths were classified as unexplained deaths, and most were in girls. Mortality in female infants was 1.3 times higher than in male infants. Discrimination, which may lead to increased mortality among female children, has been the subject of many previous studies. The World Health Organization has reported that the sex disparities in health and education are higher in South Asia, including India, than anywhere else in the world. ${ }^{6}$

The principal causes of infant mortality in India are low birth weight, birth injury, diarrhoeal diseases, and acute respiratory infection. ${ }^{10}$ In our study $22 \%$ of deaths were attributed to diarrhoea, 14\% to birth asphyxia, $12 \%$ to immaturity, and $11 \%$ to respiratory infection. The numbers of male and female infants dying of birth asphyxia, septicaemia, immaturity, and congenital anomalies were matched and not significantly different. However for the preventable and treatable illness of diarrhoea, there were twice as many deaths among girls compared with boys.

Verbal autopsy is a standard, well documented, and validated method of finding cause of death in a developing country like India. ${ }^{11-13}$ Due to paucity of resources, the cause of every death occurring outside a hospital or medical centre cannot be certified after a postmortem examination. The sample registration system of India also depends on verbal autopsy to classify deaths by cause, particularly in rural areas. ${ }^{14}$ In our study, the information collected by the auxiliary nurse midwives was scrutinised during monthly meetings with the paediatrician before the cause of death was agreed. Most data were collected within one month of the date of death, so that the period was not too long to influence recall.

For decades international public health efforts have been largely directed at reducing infant and child mortality. Worldwide a staggering 8.4 million children die each year before the age of 1 year. ${ }^{15}$ According to the United Nations, the global infant mortality declined from 93 per 1000 in $1970-5$ to 51 per 1000 in 2000. However the rate in the least developed countries is almost 10 times higher than in the more developed countries, at 89 versus 9 per 1000 live births. ${ }^{16}$ Infant mortality in India is 68 per 1000 live births $^{17}$ and was 63 per 1000 live births in our study area.

\section{Unexplained deaths}

In our group of unexplained deaths, parents were not able to give a satisfactory explanation for death or give a history of any illness like cough, fever, or diarrhoea on the day before death. Most deaths in this group were in female infants-three times more than that in boys (33 v 11) -and most occurred soon after birth. Could such deaths be an extension into the early neonatal period of female feticide?

The mean per capita income of families in which infants died of unexplained causes was higher than families in which infants dies from diarrhoeal diseases. Therefore it seems that any sex discrimination cannot be explained by extreme poverty. This has also been shown in a previous study. Booth et al found that fetal sex determination was more common among families with higher incomes. ${ }^{18}$ The sex ratio in different states of India also bears testimony to this trend. The state of Punjab, which has one of the highest per capita incomes in India (19 001-22 000 rupees per year) has one of the lowest sex ratios in the country (874 females:1000 males), while poor states like Bihar and Orissa (4001-7000 rupees per capita income) have sex ratios of 921 and 972 females per 1000 males, respectively. ${ }^{1}$

As this was a retrospective study we could not look at the circumstances surrounding these unexplained deaths. It would be interesting to know if there was more malnutrition and a shorter duration of breast feeding in children who died from unexplained causes. Further community based prospective studies are needed to examine these issues. Though the 1994 act attempted to alter the adverse sex ratio by banning sex determination tests, this cannot change the attitudes of people towards female infants. Improved access to health care and education of health professionals to pay attention to girls would be beneficial. 


\section{What is already known on this topic}

There are more men than women in India

Sex discrimination and bias in favour of male children results in selective termination of female pregnancies

Mortality is high in female infants, girls, and young women

\section{What this study adds}

There is an excess of female deaths due to easily treatable conditions

There are a large number of unexplained female deaths, which may be considered as deaths under suspicious circumstances

Contributors: RK, AK, and JMP designed the study. RK, AK, and JFV collected the data.. RK, AK, and VS analysed the data. $\mathrm{RK}, \mathrm{AK}, \mathrm{JFV}$, and JMP wrote the paper. RK is guarantor. Contributors: See bmj.com

Funding: None.

Competing interests: None declared.

1 Census of India, 2001. Provisional population totals. www.censusindia.net (accessed 15 Apr 2003).
2 Lopez AD, Ruzicka LT, Waldron I. Sex differentials in mortality. Canberra: Australian National University, 1983.

3 Kulkarni S. Sex determination tests in India: a survey report. Radical Jour nal of Health 1986;1:99.

4 Centre for Enquiry into Health and Allied Themes (CEHAT) and others $\mathrm{v} / \mathrm{s}$ Union of India and others. Law Journal Supreme Court Cases 2001;5:577-80.

5 Ghosh S. The female child in India: a struggle for survival. Bull Nutr Found India 1987;8:4.

6 Claeson M, Bos ER, Mawji T, Pathmanathan I. Reducing child mortality in India in the new millennium. Bull World Health Organ 2000;78:1192-9.

7 Chatterjee M. A report on Indian women from birth to twenty. New Delhi: National Institute of Public Cooperation and Child Development, 1990. 8 Das Gupta M. Selective discrimination against female children in rural Das Gupta M. Selective discrimination again
Punjab, India. Popul Dev Rev 1987;13:77-100.

9 Choudhary R, Sharma A, Agarwal KS, Kumar A, Sreenivas V, Puliyel JM. Building for the future: influence of housing on intelligence quotients of children in an urban slum. Health Policy and Planning 2002;17:420-4.

10 Park K. Indicators of MCH care. In: Park's textbook of preventive and social medicine. 15th ed. Jabalpur: Banarsidas Bhanot, 1997:370-80.

11 Bang AT, Bang RA. Diagnosis of causes of childhood deaths in developing countries by verbal autopsy: suggested criteria. The SEARCH team. Bull World Health Organ 1992;70:499-507.

12 Datta N, Mand M, Kumar V. Validation of cause of infant death in the community by autopsy. Indian J Pediatr 1988;55:599-604.

13 Shrivastava SP, Kumar A, Kumar Ojha A. Verbal autopsy determined causes of neonatal deaths. Indian Pediatr 2001;38:1022-5.

14 Registrar General, India. Survey of cause of death (rural), India-manual of instructions, part 1. New Delhi: Vital Statistics Division, 1991.

15 Nakajima H. Director-general's message. In: World Health Report 1996. Geneva: World Health Organization, 1996.

16 World population prospects: the 1996 revision. New York: Department of Economic and Social Affairs Population Division, United Nations, 1997. 17 International Institute for Population Sciences and OCR Macro. National family health survey (NFHS-2), India 1998-99. Mumbai, India: IIPS, 2002. 18 Booth BE, Verma M, Beri RS. Fetal sex determination in infants in Punjab, India: correlations and implications. BMJ 1994;309:1259-61.

(Accepted 15 April 2003) 